\title{
Democracia, neoliberalismo y la lucha por la emancipación
}

\section{Pablo González Casanova}

En este número sobre las Elecciones Federales de 2012 Desacatos dedica la sección "Legados" a tres textos de un destacado académico, pionero en los estudios sobre la democracia mexicana. Cuando solicitamos su permiso para incluirlos en la revista, Pablo González Casanova comentó que esperaba que en las elecciones de 2018 no fuera necesario, una vez más, publicar estas reflexiones.

\section{ÉSTA NO ES DEMOCRACIA*}

$\mathrm{S}$ i razonamos y hablamos con exactitud podemos decir que ésta no es democracia. A lo más es un camino en que si el pueblo se organiza y lucha pacíficamente en defensa del sufragio efectivo, puede lograr que se reconozcan las irregularidades de las elecciones del 2 de julio y que éstas se revisen e incluso que las elecciones se anulen.

Más difícil parece que se esclarezcan de tal modo que no haya lugar a dudas sobre López Obrador como el candidato triunfante, y que así lo acepten el PRI y el PAN, la Presidencia de la República, la patronal y las antiguas y nuevas metrópolis de Washington y Madrid, con poderosos aliados y subordinados, $y$ con los "medios de masas" que ya proclamaron su gloriosa victoria.

Las elecciones de 2006 no son unas "elecciones de Estado" como las anteriores, sino el nuevo tipo

* Publicado el 12 de julio de 2006 en La Jornada. de elecciones del Estado-mundo, trasnacional y emergente que cuenta entre sus "nódulos" o colaboradores asociados y subordinados a numerosos Estados y regímenes políticos de las metrópolis y de las periferias.

Todos los Estados y regímenes políticos del mundo se encuentran desde 1972-1980 — desde Pinochet, Reagan y la Thatcher- en proceso de desestructuración y restructuración funcional. El objetivo final del nuevo modo o modelo de dominación y acumulación es lograr algo que combina lo funcional con lo dialéctico y con lo práctico, y a lo que los nuevos "expertos" llaman "gobernanza". Por "gobernanza" entienden el arte de construir Estados, gobiernos y elecciones funcionales al Estado Trasnacional emergente, el cual integra a los complejos empresariales-militares que lo crean para asegurar su dominación y acumulación. La "gobernanza" se hace efectiva con "estrategias de largo alcance" que se aplican entre luchas, enfrentamientos y negociaciones, escogiendo con un sentido práctico las medidas que se toman en un momento

\section{Democracy, Neoliberalism and the Struggle for the Emancipation}

Pablo González Casanova: Instituto de Investigaciones Sociales,

Universidad Nacional Autónoma de México, Distrito Federal, México casanova@unam.mx

Desacatos, núm. 42, mayo-agosto 2013, pp. 203-213 
y lugar dados para alcanzar los objetivos de sus "valores e intereses" en forma inmediata, o en varias etapas, cuando sea necesario.

Así, es un error pensar que la elección de López Obrador sería la más funcional para los ricos y los poderosos, pues si éstos pueden, impondrán a Calderón, quien abierta y reiteradamente está ofreciendo darles todo lo que piden. Es más, López Obrador (AMLO) les preocupa por el tipo de ofrecimientos y apoyos populares que tiene y que no pocos de ellos consideran contrarios a sus intereses, pues "piensan que México - a decir de un analista del Financial Times - cumple una función vital para la maquinaria industrial de Estados Unidos como fuente de trabajo barato, esencial para mantener su competitividad, especialmente en los sectores de la agricultura". El mismo analista advierte que varias encuestas revelan el temor de que AMLO sea otro Chávez u otro Evo Morales, y sostiene que hasta han hecho cálculos de que los ahorros con que AMLO asegura que va a financiar su programa social no
Otra posición en la -amplia- izquierda, entre los "grandes intelectuales", numerosos obreros y cuadros de sindicatos y representantes genuinos de pueblos y ejidos, maestros y estudiantes, empleados, marginados urbanos y semiurbanos, pequeños propietarios, trabajadores de la cultura y de los medios - y es, sin duda, la mayoritaria cuando se ve y no se miente sobre su presencia en las calles y plazas de México- es la que apoya a López Obrador en el proceso electoral y considera que AMLO va a ser un gran gobernante, y que "sí le va a cumplir al pueblo".

Cuando se piensa en términos de una izquierda o fuerza ciudadana, obrera, campesina y popular amplia, se advierte que las organizaciones de los pueblos y los movimientos sociales autónomos de los partidos políticos no tienen todavía la fuerza necesaria para hacer una política a la vez funcional y flexible, práctica o de corto plazo y estratégica o de largo plazo. Su principal debilidad se muestra en ese punto. Aun así parece necesario llamar a que su madurez las lleve a unirse en la exigencia de respetar el voto, como lo hicieron en su exigencia de no tergiversar y manipular las leyes y las instituciones cuando el gobierno intentó desaforar a López Obrador.

Hoy claramente toda la izquierda debe tomar una medida de efectos prácticos e inmediatos, a reserva de que cada vez sean más gentes quienes construyan tanto una política de corto como de largo plazo, y que sin olvidar los principios ni negociar con ellos muestren su firmeza y moral pública en la verdadera defensa de la lucha legal y pacífica de los pueblos, los ciudadanos y los trabajadores de México.

Es de vida o muerte lograr la flexibilidad en las posiciones que tomen las izquierdas y los movimientos más o menos progresistas o radicales, con decisiones y provisiones que muestren a la vez su firmeza y tenacidad en la lucha por respetar y hacer respetar su identidad para construir una alternativa de democracia con pluralismo ideológico y religioso, con autonomía de pueblos y de naciones, y con un proyecto anticapitalista que dé término al colonialismo cibernético excluyente y rapaz con que los complejos militares-empresariales pretenden sivos que el PRI. 
fundar su "gobernanza" al tiempo que desatan la "política sucia" - “dirty politics"- y el máximo terrorismo de Estado - de un Estado multinacional-, mediante la guerra de varia intensidad, abierta y encubierta, formal e informal, cuyas acciones de destrucción de pueblos como Afganistán, Iraq, Palestina son tan evidentes como cínica y autodestructiva es la forma en que plantean la lucha contra Cuba e Irán, que sólo para una mente insana no implica una situación mundial al filo de la "Destrucción Mutua Indudable" - "Mad" es la sigla en inglés de mutual assured destruction y sinónimo de "loco" en ese mismo idioma-.

La necesidad de detener todas estas amenazas y muchas más se confirma cuando otro peligro de la nueva guerra se configura con el bloque inmenso de Corea del Norte, China, Rusia, Pakistán y muchos otros países que cuentan con armas nucleares y cientos y cientos de lanchas y naves atómicas, quienes sin duda se preparan a responder con toda su fuerza en un escenario de insensatez que haría de esta nueva guerra mundial del capitalismo corporativo el más miserable desenlace de la historia humana.

México tiene una posición geopolítica que le permite influir a nivel universal imponiendo las formas legales de lucha y el derecho a organizarse pacíficamente para alcanzar metas cada vez más profundas. Por eso las distintas posiciones de quienes luchamos por una verdadera democracia, libertad y justicia social - como la otra campaña y sus adherentes- debemos en este momento impedir que se viole el voto popular, y si creemos que López Obrador ganó, debemos decirlo públicamente, como lo hizo el delegado Zero de los zapatistas. Alcanzar esta primera victoria mientras conservamos la autonomía plena para seguir luchando, cada uno "a su modo" de pensar y sentir, no impedirá por supuesto el que cada uno espere contar con más y más movimientos sociales, de pueblos, ciudadanos, trabajadores intelectuales y manuales, de medianos y pequeños empresarios, e incluso con algunos no tan pequeños, que con la sobrevivencia de México defiendan la vida y la libertad, así como el derecho a disentir y discutir entre los propios partidarios de un mismo ideal.

Si el razonamiento anterior parece mera retórica o mera "opinión", no lo es. Corresponde a un apremio práctico que podemos hacer efectivo. Afirmar nuestra identidad personal y de grupo y nuestra solidaridad entre diferencias, permitirá construir la alternativa de un mundo posible y necesario.

$$
\sim \omega
$$

\section{¿A DÓNDE VAMOS?**}

Un poco de historia de la actualidad se hace necesaria. La grave situación del país implica detenerse a pensar en medio de la batalla por el petróleo... En la época de Díaz Ordaz ya empezaron las políticas financieras neoliberales. Sus primeras víctimas fueron los profesionistas y las universidades. Recuérdese el movimiento médico del 66, y el movimiento estudiantil del 68. Una de sus causas fue la falta creciente de recursos para fines sociales; otra, la crisis del autoritarismo generalizado que escondía tanta hipocresía y violencia. Los movimientos tuvieron también como origen el nuevo planteamiento de una sociedad mejor, frente a las corrientes cada vez más deterioradas del nacionalismo revolucionario, de la socialdemocracia acomodaticia y del socialismo burocrático y sus conocimientos oficiales.

Las políticas neoliberales continuaron avanzando. Los obstáculos que enfrentaron fueron efímeros y poco consistentes. De 1970 a 1976 se inició un endeudamiento externo creciente que llevaría a la nueva dependencia del Estado. De 1976 a 1982 aumentaron los ataques de las grandes empresas a los funcionarios públicos calificados de populistas, en quienes destacaron sus contradicciones. La

\footnotetext{
** Publicado el 4 de agosto de 2008 en La Jornada.
} 
frivolidad del discurso oficial se hizo evidente en ese sexenio y la nacionalización de la banca sólo echó fuego a la hoguera.

La cólera de los afectados en sus grandes intereses, lejos de amainar, se hizo terminante. Si hasta entonces el gobierno se veía obligado a obedecer el perfil que los empresarios le trazaban para la designación del secretario de Hacienda, desde 1982 los tomó muy en cuenta para la elección de un candidato a la Presidencia de la República "políticamente correcto" que reiniciara el proceso de privatización de la nación entera, empezando por devolver la banca a sus antiguos propietarios. Éstos, a poco de comprarla, la vendieron a los grandes bancos de Estados Unidos y Europa.

Así, por etapas bien calculadas, según la correlación de fuerzas, empezó el paso de mando del PRI al PAN, y de un sistema en que predominaba el partido del Estado - el partido como la institución electoral del Estado- a un sistema político con "partidos de Estado", cuya gama ideológica se enriqueció desde el ingreso del Partido Comunista con genuinos intentos por sus militantes para fortalecer la "vía pacífica", intentos que pronto terminaron con muchos de ellos asesinados y otros, tal vez más numerosos, cooptados. Por supuesto subsistieron algunos excomunistas respetables.

En las mismas décadas de los setenta, la eliminación y la cooptación pusieron también en crisis a las guerrillas de presión social y negociación social, como la de Genaro Vázquez, quien fue asesinado al no transformar la negociación social en negociación personal. Después de los años sesenta, en los movimientos rebeldes armados proliferó la idea de una revolución del nuevo tipo, que desde los años sesenta luchaba por la toma del poder como objetivo estratégico. En todo caso, los sucesivos gobiernos priistas, mediante la represión y la cooptación, habían controlado y siguieron controlando las "insurrecciones" de mineros, ferrocarrileros, trabajadores de la construcción..., al mismo tiempo que fortalecían el sindicalismo oficial y rehacían

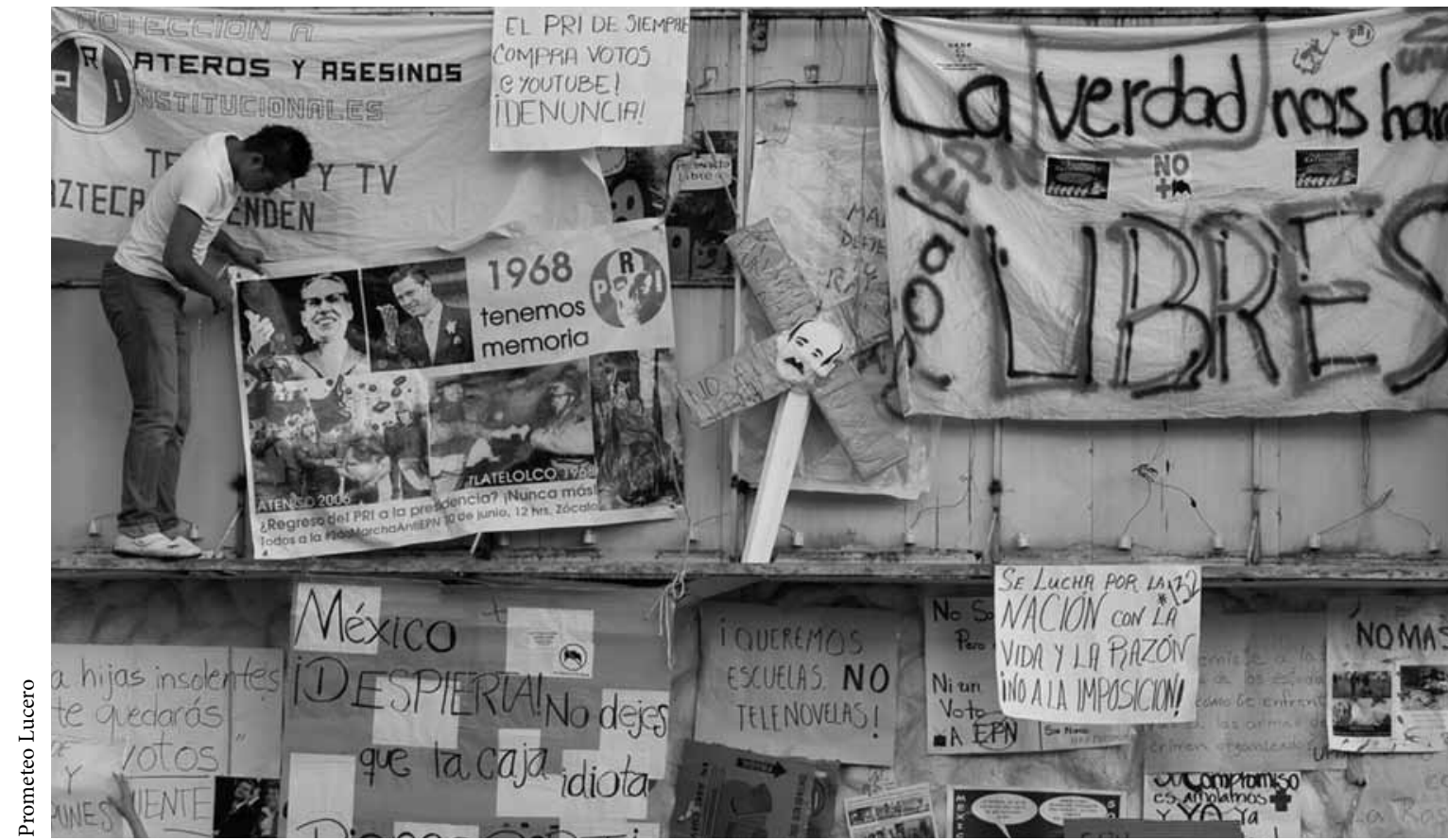

Marcha \#YoSoy132 hacia Televisa, en la ciudad de México, 24 de junio de 2012. 
las políticas sociales, culturales, económicas y financieras que, entre incontables dificultades, contradicciones y debilitamientos trataban de mantener como política de un Estado social y nacional cuyas fuerzas e integrantes se aburguesaban cada vez más, no sólo en el terreno económico-social, sino en el terreno ideológico, político y militar.

La crisis del "Estado social" comprendió incluso a muchos de los grupos opositores más radicales, y derivó en el florecimiento de un conformismo jocoso y costoso, de una negociación lucrativa y entreguista, de un escepticismo racionalizador y un cinismo retador y prepotente. Una nueva cultura individualista, "realista, corporativa”, se extendió por todas partes, en un proceso de "percolación", parecido al de las pandemias que pasan de mostrar síntomas aislados a extenderse en regiones enteras del organismo enfermo, quedando inmunes sólo unos cuantos grupos e individuos.

\section{Posponer el diluvio}

La historia de hoy puede resumirse en la de una ocupación integral del Estado y la nación. La privatización es el nuevo nombre de la ocupación. Con la creciente deuda externa las grandes empresas consolidaron el triunfo que habían alcanzado al impedir la reforma fiscal que las afectaba; el gobierno en turno logró mantener ciertas políticas sociales que aseguraban su estabilidad. Se fue acostumbrando a una lógica política de "posponer el diluvio". Hizo concesiones a futuro con tal de resolver problemas inmediatos. La deuda externa no dejó de incrementarse. Con ella, los acreedores lograron influir más y más en el presupuesto de ingresos y egresos del país. Todo se hizo como si estuviera premeditado. Entre negociaciones de cúpula, los prestamistas pedían un poco menos de lo que pedirían después.

Con la pérdida de la política económica no sólo vino una merma del poder del presidente y el Congreso, sino la pérdida de autonomía del gobierno en la política monetaria: el Banco Central pasó a ser dirigido por un funcionario que desde entonces es designado por el Banco Mundial, por supuesto en formas mediadas y encubiertas.

La posibilidad de apoyar a los exportadores con devaluaciones de la moneda, o la de apoyar a los patrones con disminuciones al salario real, mediante la congelación de salarios y aumento de los precios, ya sólo fue un privilegio de las grandes fuerzas financieras y patronales y monopólicas predominantemente extranjeras.

La ocupación como privatización fue legitimada por los economistas neoliberales que pretendían representar "la última palabra de la ciencia", costumbre que les es característica desde Adam Smith y que ellos cultivan, aunque sin la misma franqueza, pues no dicen, como aquél, que la liberalización de los mercados favorece siempre a los países más industrializados y poderosos en detrimento de los más débiles, y a las empresas más fuertes a costa de las más débiles.

La ocupación integral no descuidó el terreno militar: incrementó la formación de cuadros en las escuelas del imperio e "internalizó" un nuevo concepto de la guerra en que el militar deje de sentirse defensor de la patria frente a los enemigos extranjeros, y se prepare para luchar contra su propio pueblo y contra los grupos criminalizados por el gobierno en turno, preparación que lo lleva a participar hoy en la guerra de competencia por el narcotráfico, y a intimidar, acosar y vejar a pueblos indios potencialmente despojables y desechables, que ocupan territorios ricos en recursos naturales de los que las compañías sueñan con apoderarse.

En el campo de la educación y la cultura, la ocupación tuvo importantes triunfos en la enseñanza primaria y secundaria, con reformas a los planes de estudio que con el pretexto de dar más importancia a las ciencias no enseñan ni las ciencias ni las humanidades, y hacen olvidar la historia de México y el mundo. El manejo del presupuesto de egresos tendió a disminuir los recursos humanos para la formación de técnicos de alto nivel en la agricultura, los energéticos, las comunicaciones y transportes, la 
industria y los servicios. Después trató de privatizar del todo a la educación superior y se enfrentó a una heroica resistencia que encabezaron los estudiantes de la UNAM hasta detener el golpe. No por eso cejaron los privatizadores. Sus "expertos" de Estados Unidos y Europa siguieron proponiendo como lo más moderno una educación de pocos, para pocos y con pocos, la más "funcional" según ellos, y sí lo era para el país que tenían en mientes, un país carente de mercado de trabajo para los egresados de las escuelas profesionales -médicos, ingenieros agrícolas, petroleros y civiles, economistas, abogados, etcétera- en un país al que pensaban quitarle y le estaban quitando y debilitando su seguridad social, sus empresas públicas, sus actividades culturales para los pueblos.

La demanda de privatización y de educación elitista no quería sólo ajustar la oferta a la demanda de empleos "innecesarios". También buscaba la clausura institucional de la universidad mexicana $-y$ latinoamericana-, esa casa que difunde la razón, el todo aquello que causa terror a quienes no tienen la razón ni el derecho y que recientemente han calificado a la universidad de vivero de terroristas.

La ocupación integral neoliberal de los centros educativos logró de todos modos obtener importantes triunfos. Hoy se encuentran sin universidad y sin empleo una inmensa cantidad de jóvenes, al tiempo que baja la escolarización y suben los niveles de analfabetismo e ignorancia.

Se trata de una eficiente política para el subdesarrollo por la que sus artífices son "evaluados" como sobresalientes.

En las luchas por la cultura, la ocupación neoliberal logró un triunfo increíble cuando el Poder Legislativo privatizó las funciones públicas de la televisión y de los medios de comunicación de masas, lo que permitió a los ocupantes quedarse con la política de los "conocimientos prohibidos". Del "lenguaje políticamente correcto" y de una "realidad virtual" unánimemente difundida como imperante espejismo de oasis sin agua, y de un México

feliz habitado por débiles mentales y gobernado por personas realmente serias y respetables que son objeto de infundios lanzados por ambiciosos corrompidos - como los de "La consulta" - y por alborotadores que arman escándalos en lugar de ponerse a trabajar.

La ocupación integral también logró combinar la cultura autoritaria y corrompida de las oligarquías republicanas con la cada vez más influyente de los encomenderos y de las oligarquías mentalmente colonizadas por la España de Carlos V y por la "anglo" neoconservadora, que maltratan el idioma español queriéndolo hablar como los españoles o como si fueran estadounidenses.

En el terreno de la política y la sociedad, de las finanzas y la economía, la ocupación neoliberal logró privatizar al Estado mismo a niveles sin precedente. En México, como en otros países del mundo, se impuso la cultura del "mentiroso en palacio", y de "la hipócrita Albión", expresadas por los nuevos "señoritos" posfranquistas y por los voceros de Washington, las mafias de Wall Street y los rancheros de Texas o California.

A esas herencias enajenadas se añadió la cultura de la trampa de los caciques nacionales, blancos y mestizos, que se juntó a la cultura de la trampa de los gángsters electorales de Florida, y de otros estados del "vecino país del norte". La representación de la "representación democrática" puso en escena falsas discusiones legislativas que pretenden deliberar con toda libertad un proyecto que aprueban en lo fundamental, por el que venden su voto u obedecen a la superioridad.

La ocupación más a fondo se da en la separación creciente entre "el México formal" y "el México real" con métodos inusualmente legitimados de violar las formas en el momento mismo de aplicarlas. Así ha aparecido un nuevo tipo de golpes de Estado que ocurren a la hora de las elecciones y no después, o el asesinato de numerosos periodistas combinado con el respeto de la libertad de crítica y expresión, o las reformas de hecho a la Constitución sin que se hayan reformado los preceptos correspondientes - por 
ejemplo a Petróleos Mexicanos-, combinaciones difíciles de explicar hasta para muchos "entendidos", cuando no se advierte que las leyes no se usan para regular, sino para legitimar o criminalizar.

La ocupación privatizadora ha logrado separar como nunca a "la clase política" de sus "bases sociales", con lo que debilita a aquélla y éstas, y deja que todas se desmoralicen en medio de una crisis moral e ideológica insuperable mientras sus víctimas no piensen construir otro mundo alternativo y las organizaciones necesarias para alcanzarlo. Mientras tanto, la manera en que "la clase política" - o una parte de ella- entiende "lo político" consiste en someterse más y más a los ocupantes con una opción: el servilismo o el arreglo en "lo oscurito".

Ciertamente en todo este terreno la responsabilidad de las fuerzas independientes o alternativas es muy grande y difícil de asumir, pues enfrentan una separación estructural entre los pueblos y trabajadores pobres, no organizados ni con derecho a organizarse y negociar - por un lado-, y los trabajadores que gozan más o menos de esos derechos, aunque las organizaciones y negociaciones sean en circunstancias cada vez más adversas, dadas las políticas neoliberales que amplían el campo de "lo no negociable".

La separación social, cultural, política e ideológica entre los pueblos y trabajadores excluidos y los organizados plantea la necesidad de tender puentes, sobre todo en las luchas cruciales por objetivos que son a la vez inmediatos y de largo plazo.

El respeto a la autonomía de quienes juntos den una misma batalla será tan necesario como la conjunción de sus fuerzas. En la unión por metas concretas con autonomía de los participantes se encuentra el último recurso de que dispone México para no entrar en una situación caótica en que a la ocupación del país mediante la privatización de sus bienes y recursos se añada la privatización mediante la intervención militar de "la comunidad internacional" encabezada por Estados Unidos.

La ocupación privatizadora y neoliberal de México ya es colosal. Además del dominio de la política crediticia y monetaria, de las finanzas públicas y de los medios de comunicación de masas, el proceso de ocupación integral abarca la privatización de correos, carreteras, puertos y aeropuertos, líneas aéreas y comunicaciones telefónicas, grandes diarios y fuentes de información, tierras fronterizas y playas, y territorios en que reinan las compañías herederas de Mamita Unay.

El nuevo tipo de megaempresas dispone en cada una de toda la cadena que le permite dominar a los mercados. Cada una posee sus propias fuentes de financiamiento, de tecnología y producción, de comunicación, de transporte y almacenamiento, de distribución al mayoreo y al menudeo, de insumo y seguridad, todo a cargo de sus sucursales, de pequeñas y medianas empresas subcontratadas, y de tendajones y vendedores ambulantes.

Es más, al refuncionalizar a los Estados y a los sistemas políticos, las megaempresas logran convenios y contratos, concesiones, exenciones, difericiones y cancelaciones de pagos billonarios, así como leyes, decretos y acuerdos que les son altamente favorables.

Desde el TLC hasta hoy, las megaempresas se han ido apoderando de más y más territorios y tierras, y de los mercados nacionales y regionales de todo el país. México depende de las megaempresas y sus gobiernos, entre los cuales está incluido cada vez más "el nuestro". Hoy dominan el mercado del dinero, del crédito, de los granos y de la fuerza de trabajo.

Conocedoras de sus triunfos, las megaempresas y los complejos militares empresariales están conscientes también del creciente descontento que generan entre desempleados, desplazados y los despojados de tierras y trabajo, educación y seguridad, y hasta de medicinas y alimentos.

Las megaempresas tienen una clara idea de los peligros que las amenazan en el futuro inmediato y están preparadas para enfrentarlos. Ya pueden sus voceros anunciar que México será la cuarta potencia mundial en pocos años - como afirmó Calderón recientemente- o que "el peligro de la crisis está bajo control”, y otras linduras; pero a las 
predicciones y "simulaciones de futuros" de los expertos neoliberales mexicanos se añade una predicción real, concreta: un muro gigantesco que separa a todo México de Estados Unidos y Canadá.

El inmenso muro da clara idea del futuro que nos aguarda de continuar el camino que hemos seguido en los pasados 30 años. Sin querer, "Norteamérica" nos amenaza y nos junta con América Latina e Indoamérica, con sus pueblos y trabajadores. Con su Gran Muro como señal que hasta los ciegos ven, nos invita a no caer en el grave error de una Palestina invadida y un terrorismo de la resistencia, sino a fortalecer la estrategia de organización y lucha pacífica que la inmensa mayoría del pueblo y los trabajadores de México insistentemente buscan, y que los propios grupos de defensa armada de las poblaciones están de acuerdo en sostener en todo lo que se pueda y mientras se pueda, incluyendo siempre en su más profunda cultura rebelde el rechazo a los actos terroristas como actos crueles que hieren y matan a personas inocentes.

Organizar y concientizar en cambio a la inmensa mayoría de la población con redes presenciales y a distancia que defiendan sus intereses inmediatos y pongan las bases de un mundo necesario y posible es el camino de la solución para que construyamos con otros "condenados de la Tierra" "otra democracia, otra liberación y otro socialismo", todos dentro del pluralismo ideológico y religioso con espacios laicos que ya hemos hecho nuestros, y teniendo como fuerza principal de apoyo y decisión a los "pobres de la Tierra".

Hoy todo voto contra cualquier proyecto de privatización del petróleo de PRI y PAN o sus derivados será un voto por el camino menos doloroso de la historia de México. Es posible que de triunfar el no, Estados Unidos y sus aliados europeos pretendan quitarnos el petróleo, y lo que no han ocupado aún quieran quitárnoslo con una de esas guerras "humanitarias" que organizan en sus luchas depredadoras por la libertad de mercados y la democracia que no practican, y contra el terrorismo en que son expertos.
A los intervencionistas habremos de contestarles con el presidente católico Benito Juárez: "Que los enemigos nos venzan y nos roben, si tal es nuestro destino: pero nosotros no debemos legalizar un atentado entregándoles voluntariamente lo que nos exigen por la fuerza". Y después recordaremos a los poetas que dijeron: "Hay en los hombres un infatigable depósito de energía moral, que les permite ser incesantemente rebeldes". O lo que nos dijeron algunos zapatistas: "Para resistir, luchar y crear se necesitan tres cosas: perder el miedo, tener esperanza y hacer fiesta. $Y$ todo sin perder la dignidad y la firmeza".

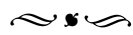

\section{NOTAS PARA UN MANIFIESTO DE LA IZQUIERDA EN EL SIGLO XXI ${ }^{* * *}$}

Un clamor resuena en todo el mundo. Todos queremos libertad, todos soñamos con la democracia. Que nos la den, que la hagamos, que la apoyen $y$, sobre todo, que luchemos por tenerla.

Pero, ¿con quién vamos a luchar, al lado y al amparo de quién queremos luchar? ¿Con quién contamos y queremos contar?

Obviamente no queremos apoyarnos en quienes entrenan a sus soldados para que al grito de libertad invadan, destrocen y saqueen pueblos enteros, y sin piedad alguna causen daños horripilantes a mujeres, niñas y niños, jóvenes y viejos, con el supuesto de que están luchando contra quienes merecieron su inmenso apoyo en armas, dinero, negocios, publicidad y diplomacia durante años y años.

No queremos apoyarnos en quienes han atacado por todos los medios a su alcance, incluidos los bloqueos, los intentos de magnicidio, las plagas, los golpes de Estado, las invasiones militares y paramilitares, las falsas y crueles guerras contra un

\footnotetext{
*** Publicado el 23 de marzo de 2011 en La Jornada.
} 
narcotráfico que les sirve como gigantesco negocio para lavar el dinero de los criminales en sus bancos y quedarse con la mayor parte; que les sirve para prestar dinero con altos intereses a los gobiernos aliados que son sus clientes en la compra de armas de mediano y alto poder, iguales o inferiores a las que también les venden a los narcotraficantes; que les sirve para mediatizar la ira del pueblo empobrecido por sus políticas privatizadoras y especuladoras y para embarcar a los jóvenes de esta América en falsas luchas de mafias que les hacen perder - con su identidad y sus vínculos sociales y familiares-el sentido de la vida y el sentido de la lucha, y con que pierden a su propia juventud, a la joven América que protestara en Chicago contra la guerra en Vietnam y se manifestara a favor de los afroamericanos y de los habitantes y movimientos sociales del Tercer Mundo de los que el Che Guevara fue su icono y que hoy constituyen el principal mercado de narcóticos del mundo, con que se destrozan y los destrozan. No queremos apoyarnos en la lucha por la libertad con el ejército que defendió durante años al Mubarak que el imperialismo también apoyó, ni en los aviones de la OTAN que durante años han estado destruyendo a Iraq y Afganistán. No queremos coincidir con quienes han declarado una guerra total contra el pueblo y gobierno de Cuba, con quienes han hecho todo lo posible por dividir y enfrentar al pueblo y gobierno de Venezuela, con quienes apoyaron y apoyan la secesión y desestabilización de la República de Bolivia.

Es más, debemos denunciar el hecho de que las potencias imperialistas encabezadas por Estados Unidos y la OTAN están aplicando la vieja táctica de mediatizar los movimientos emancipadores del pueblo para poner a sus ejércitos serviles como liberadores del pueblo que durante años y años han contribuido a oprimirlos. ¿Podemos olvidar esta vieja trampa que se ha aplicado contra nuestros pueblos desde hace más de un siglo y medio y que hoy está al orden del día en los nuevos golpes legales de Estado, y en las nuevas luchas por la libertad y

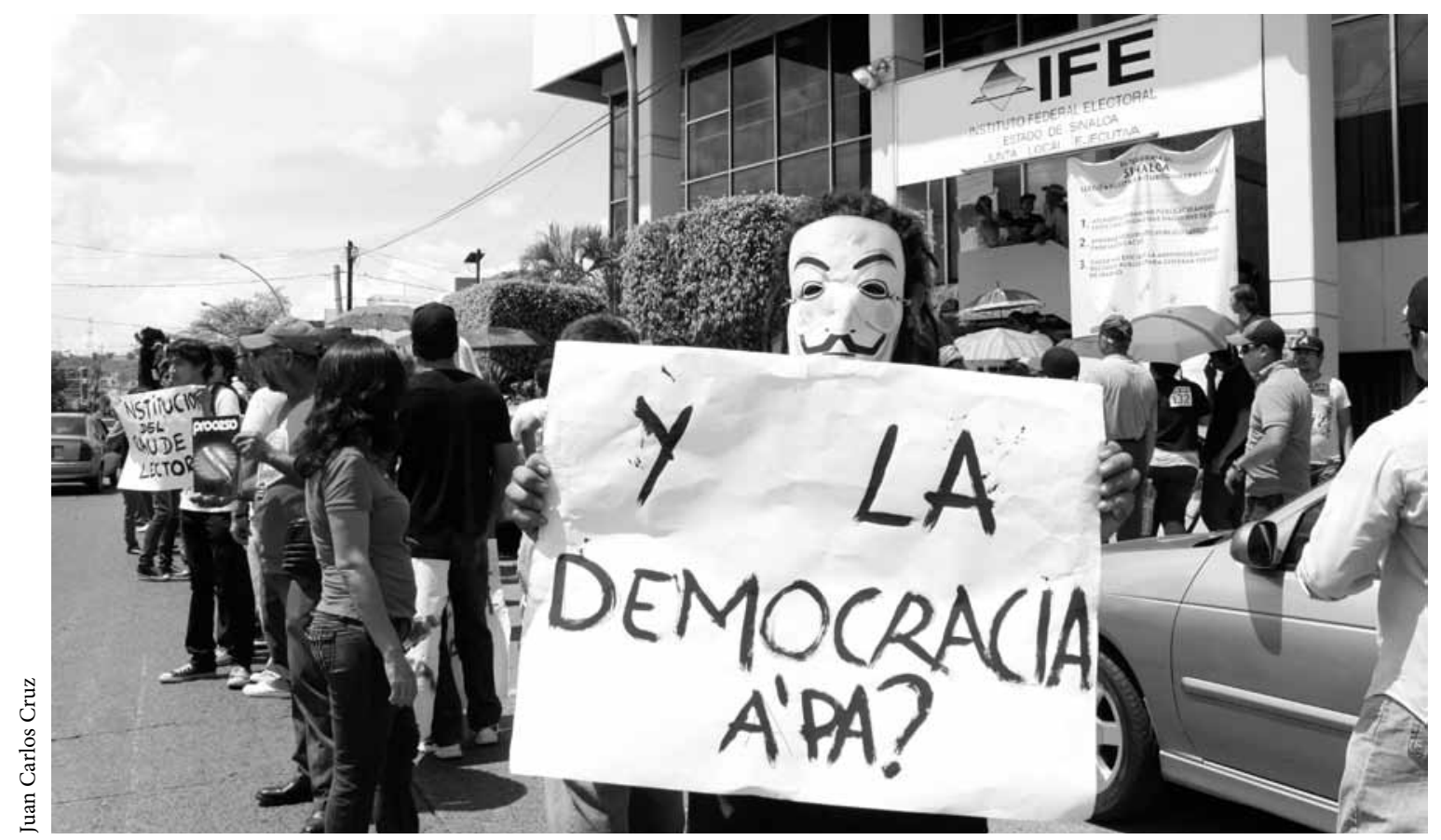

Protestas antipeña en Sinaloa, 2012. 
la democracia de un imperialismo que cada vez más oprime y despoja a nuestros pueblos y que sólo apoya a los gobiernos que le hacen crecientes concesiones a sus empresas extractivas y depredadoras?

Aclaremos de una vez por todas que nosotros queremos una libertad y una democracia de las que el imperialismo es su principal enemigo, aunque quiera nuevamente jugar con los equívocos para decir que lucha por lo mismo que nosotros. ¡Mentira! Nosotros queremos una democracia en que el pueblo gobierne y en que los gobernantes le sirvan al pueblo, gobiernen con el pueblo y se reintegren al pueblo cuando termine su mandato. Nosotros queremos una democracia en que se creen espacios de diálogo, debate y consenso a lo largo y lo ancho de toda la nación, con respeto a las distintas religiones, ideologías, culturas, razas, sexos, edades. Nosotros queremos una libertad de pensar, de estudiar, de decidir, en la que deje de estar sujeta al hambre y la miseria la inmensa mayoría de la población humana en beneficio de $200 \mathrm{mul}-$ timillonarios que juntos tienen el ingreso nacional de del mundo. ¿Es ésa la democracia que ellos quieren? ¿Es ésa la libertad que dicen defender? Por supuesto que no... Pero hay algo más que ellos no quieren: la justicia. Nosotros queremos la justicia a la persona humana; pero miremos dónde están los mentados derechos del hombre por los que ellos dicen haber luchado. Nosotros estamos por la justicia social y miremos cómo han impuesto sus políticas privatizadoras, desnacionalizadoras y desreguladoras que han acabado con los derechos de las naciones, de los pueblos y los trabajadores. Es más, nosotros queremos que la justicia social la hagan los pueblos, que los pueblos gobiernen en uso de la democracia y que los pueblos y sus integrantes hagan justicia personal, hagan justicia familiar, social, laboral, política, cultural, económica, y que la justicia social sea propia del hacer y quehacer de los pueblos y no de señorones dizque generosos o dizque humanitarios y a esa justicia social que los pueblos ejerzan en uso real de la democracia le llamamos socialismo del siglo XxI, pues no concebimos el socialismo sin el gobierno del

pueblo por el pueblo y para el pueblo, y menos el socialismo sin la libertad. ¿Y ellos? Y los supuestos y oportunistas aliados del pueblo de Libia que están bombardeando al pueblo de Libia, ¿quieren esa libertad, esa democracia y esa justicia que nosotros queremos? Por supuesto que no. Pero son unos notables farsantes que confunden y engañan con ideales fingidos.

Por nuestra parte tenemos que aclarar no sólo lo que queremos sino cómo pensamos realizarlo y hasta qué punto, en medio de las diferencias que se dan entre quienes luchamos bien que mal por la emancipación humana, y que luchamos en distintos países y condiciones...; hasta qué punto en medio de nuestras diferencias podemos encontrar algunas políticas coincidentes que nos ayuden a respetar las distintas posiciones que tenemos a reserva de que la evolución de las luchas vaya unificando criterios y experiencias. A ese respecto lo primero es no exigir que todos tengan la misma posición que uno tiene. Lo segundo es dar las razones por las que en un momento y situación dados uno toma la posición que otros no comparten. Lo tercero es ver si las razones de una toma de posición se confirman o disconfirman por la experiencia.

Señalemos como punto de partida una política global del imperialismo neoconservador y neoliberal. Desde el grito de la Tatcher afirmando que “ino hay alternativa!” los complejos empresarialesmilitares que dominan el mundo han aplicado la política de lo no negociable a las medidas de desnacionalización, privatización y desregulación por las que han empobrecido sistemáticamente a todos los pueblos del mundo, incluso a los metropolitanos. Esa política de lo no negociable está vinculada a la destrucción de los derechos políticos, laborales y sociales que implicaban una distribución del producto global y del producto nacional, menos desigual e injusta que la actualmente existente en que las naciones pobres son más pobres que hace 30 años, y los ciudadanos y trabajadores pobres y depauperados han crecido de una manera dramática.

La política de lo no negociable ha acabado con la capacidad de los partidos políticos y las organizaciones 
sociales y laborales para protestar, presionar y negociar para el cumplimiento de derechos y prestaciones sociales: ha liquidado en los hechos los derechos de la Carta Magna de cada país y de la Carta de Naciones Unidas en derechos humanos y en derechos de no intervención y libre autodeterminación de los pueblos. La política de lo no negociable ha hecho de la violación del derecho la práctica del derecho. Y esto ocurre con la práctica del derecho internacional, público, social, laboral o civil. Lo más frecuente es usar el derecho para criminalizar a las víctimas del sistema y usarlo al arbitrio de jefes y patrones.

Al mismo tiempo y en vez de reconocer los derechos políticos y sociales que tantos gastos implicaban, se han generalizado las políticas de cooptación y corrupción de funcionarios públicos, de partidos políticos y gobiernos enteros para que apliquen las medidas neoliberales contra lo ofrecido en los idearios de partidos y candidatos. El desprestigio de la democracia electoral y parlamentaria es así tan grande como el de la inmensa mayoría de los partidos de izquierda, e incluye a los candidatos socialdemócratas, socialistas, comunistas, nacionalistas, desarrollistas que teniendo nombres distintos hacen políticas neoliberales iguales... con el cinismo y la furia de quienes sólo luchan por tener puestos de elección popular.

A tan lastimosa situación de un mundo que parece haber acabado con la posibilidad de las luchas legales efectivas, se añade el inmenso desastre de la restauración del capitalismo en el bloque soviético, China y Vietnam donde los antiguos comunistas reniegan de sus antiguos héroes o los invocan diciendo que están actualizando y modernizando su pensamiento, y que sólo los conservadores se oponen a su avanzado pensamiento.

Para luchar debemos recordar éstos y otros grandes tropiezos y ver cómo se están superando entre líderes y masas, dando creciente atención a las palabras de consecuencia, a las conductas coherentes, a los líderes que igualan con la vida el pensamiento, como el comandante en jefe Fidel Castro.
Tenemos que destacar el programa de paz mundial del gobierno venezolano y la nueva lucha bolivariana que libra por el socialismo del siglo XxI, buscando resolver las contradicciones que enfrenta con la organización y concientización creciente del pueblo en un proyecto que no repita la historia pasada de las revoluciones nacionales y sociales que se volvieron populistas y acabaron reintegrándose al sistema neocolonial, hoy neoliberal.

Tenemos que destacar la lucha por el vivir bien del pueblo y el gobierno de Bolivia, pues se trata de un programa que hablando de Bolivia habla del mundo.

A otro nivel, el de los gobiernos que mandan obedeciendo a las comunidades, aparece un programa que es también de alcance universal y riquísimo en metas y medios como el movimiento zapatista de los pueblos mayas que luchan y construyen otro mundo posible en el sureste mexicano.

Al mismo tiempo necesitamos tenderle la mano a otros gobiernos progresistas que entre contradicciones están apoyando una política de paz y de respeto a las naciones y los pueblos, y si no los apoyamos en todo, apoyémoslos en lo que sean luchas por la libertad, la justicia, la democracia, la paz, y hagámosles ver que una condición evidente para el triunfo radica en que sus gobiernos y sus políticas sean gobiernos y políticas de todo el pueblo y que, sobre ese principio político, indeclinable si no quiere uno perder, enfrenten los acosos de las oligarquías, del capital monopólico y el imperialismo con medidas que tiendan a profundizar la democracia y la economía de todo el pueblo.

En cualquier caso procuremos que nuestras diferencias internas se resuelvan en formas que no nos tribalicen y nos hagan nuevas víctimas de la vieja política colonialista que aprovecha las luchas internas para las intervenciones externas, colonizadoras y recolonizadoras.

La responsabilidad que en América Latina tenemos es inmensa, pues el Nuevo Mundo saldrá del Nuevo Mundo que ya muestra su grandeza, enriquecida por todos los proyectos de emancipación humana. 